\title{
Research on the Investment Cooperation between Sichuan and Chongqing Based on the Motives of Manufacturing Transformation and Upgrading
}

\author{
Xiuzhi Wang, Xing Gao a , Ruqun He \\ College of Economic and Management, Guangxi Normal University, Guilin 541006, China \\ a1083731256@qq.com
}

\begin{abstract}
Keywords: manufacturing transformation and upgrading; government investment; industry guidance fund; Chengdu-Chongqing Economic Zone.

Abstract. Industrial transformation and upgrading is an important task of supply-side structural reform in the context of the new normal. Historically, government investment has had an important impact on industrial development. Innovating government investment mechanisms and models is a useful attempt to promote industrial transformation and upgrading in the new era. Take the ChengduChongqing Economic Zone as an example. The government investment factors in the manufacturing structure of the two cities are obvious. They focus on improving the competitiveness of ChengduChongqing Economic Zone and long-term development. The level of cooperation in the division of labor in the two cities needs to be improved to realize the transformation and upgrading of regional manufacturing. By building an industry-led fund approach, giving full play to the advantages of the market allocation of resources may be a path model worth exploring.
\end{abstract}

\section{Introduction}

While promoting the coordinated development of the regional economy and playing a decisive role in the market, it is also necessary to better play the guiding role of government investment. Government investment plays an important role in the development of the industry in the western region. Under the background of the new economic normal and supply-side structural reforms, the western region should more effectively exert the dynamic role of government investment in promoting industrial restructuring and upgrading. Therefore, strengthening local government investment cooperation has become a realistic topic worth exploring. As a key area in the western region and the former third-line construction, the government investment factor in the development of the Chengyu Economic Zone is more prominent. From the perspective of history and reality, there is a special source of cooperation and cooperation between the two places. The two places should uphold the concept of division of labor and cooperation, based on the existing manufacturing structure, focus on long-term development, and promote the transformation and upgrading of the manufacturing industry through regional government investment cooperation. The Nineteenth National Congress report puts forward: "Deepen the reform of the investment and financing system and bring into play the key role of investment in optimizing the supply-side structure [1]" Local governments should effectively play a guiding role of government investment in supply-side structural reform and innovate the investment system. With the mechanism, the government funded the establishment of industry guidance funds, operated with market mechanisms, optimized the industrial structure from the perspective of regional cooperation, and promoted the optimization of industrial structure with the industry-guided fund cooperation model.

\section{Current Status of Manufacturing Industry in Chengdu-Chongqing Economic Zone}

In 2014, the State Council put forward guiding opinions on the overall development of ChengduChongqing Economic Zone. The Chengdu-Chongqing Economic Zone mainly includes 31 districts and counties in Chongqing and 15 provinces and cities in Sichuan. It spans two large cities and is representative in the western region. It is one of the regions with the most comprehensive strength in 
the western region and is also the size of the western region. The largest and most economically advanced areas have broad space for development in the western region.

\subsection{The Structural Homogeneity of the Two Manufacturing Industries is Obvious}

According to Table 1, the structure of the two manufacturing industries has high similarity. In 1978, the similarity coefficient of the industrial structure was higher. From 1993 to 2002, the similarity coefficient of the industrial structure began to decline slightly, in 2005-2008. The coefficient of similarity began to "bounce" and showed a rising trend. This means that the development of the manufacturing industry will enter a new state of co-opetition. The similarity coefficient will decline slightly in 2011-2015, but it is still at a relatively high level. The results show that the industrial structure of Chengdu and Chongqing is very similar. The industrial structure of Chengdu-Chongqing Economic Zone is more homogeneous, and the industrial industry is not significantly different. Under this trend, we should pay great attention to how to exert the government's guidance and market allocation forces in regional development [2].

Table 1. Similarity coefficient of industrial structure in Chengdu-Chongqing Economic Zone

\begin{tabular}{|c|c|c|c|c|c|c|c|c|c|c|}
\hline years area & 1978 & 1993 & 1996 & 1999 & 2002 & 2005 & 2008 & 2011 & 2013 & 2015 \\
\hline Sichuan-Chongqing & 0.83 & 0.76 & 0.75 & 0.69 & 0.65 & 0.68 & 0.70 & 0.69 & 0.67 & 0.65 \\
\hline
\end{tabular}

\subsection{Manufacturing Advantages the Industry is More Concentrated}

According to the statistics of the top 50 industrial enterprises in Chongqing in 2016, according to the distribution of industries, dominant enterprises are mainly distributed in the automobile manufacturing industry, computer electronic information, and other electronic equipment manufacturing industries and electrical machinery manufacturing industries. Seven industry classifications. Automobile and other motor vehicle industries are important industries in Chongqing's industrial industry. There are 11 auto manufacturers that occupy the top 50 in the country. According to the statistics of the top 50 Sichuan industrial enterprises in 2016, the dominant industries in Sichuan are mainly concentrated in the electronic information industry, oil and gas exploration industry, wine, beverage and refined tea manufacturing industries, and railways, ships, aerospace and other industries. Transport equipment manufacturing, tobacco products, automobile manufacturing, etc., and the production of key enterprises in the top 50 in the province continued to increase [3]. There are certain similarities in the distribution of the top 50 industries in Chengdu-Chongqing Economic Zone, but there are also certain differences, which further laid the foundation for promoting the interaction of the industrial structure of Chengdu-Chongqing Economic Zone.

\section{Opportunities for Government Cooperation in Chengdu-Chongqing Economic Zone}

\subsection{Signing of Favorable Agreements}

Before Chongqing was directly under the jurisdiction of the People's Republic of China, although Chongqing was a municipality directly under the Central Government, it was still within the jurisdiction of Sichuan Province. Its geographical location was destined to require the division of labor among the industries in Sichuan and Chongqing [4] and a series of cooperation between Sichuan and Chongqing. The agreement and a series of symposiums held will lay a certain foundation for cooperation in the region.

Table 2. The agreement and a series of symposiums held will lay a certain foundation for cooperation in the region.

\begin{tabular}{|c|c|}
\hline time & content \\
\hline $\begin{array}{l}\text { December } \\
2001\end{array}$ & Chengdu and Chongqing signed "Minutes of the Chengdu-Chongqing Friendship Cooperation Conference" \\
\hline February 2004 & Chengyu Economic Zone signed the " $1+6 "$ agreement \\
\hline April 2007 & $\begin{array}{c}\text { Sichuan and Chongqing have signed the "Agreement on Promoting Sichuan-Chongqing Cooperation for a Completely Built } \\
\text { Economic Zone" }\end{array}$ \\
\hline October 2008 & $\begin{array}{c}\text { Sichuan and Chongqing signed the "Framework Agreement on Deepening Economic Cooperation between Sichuan and } \\
\text { Chongqing" }\end{array}$ \\
\hline May 2015 & $\begin{array}{c}\text { The Sichuan and Chongqing governments signed the "Memorandum on Strengthening the Cooperation between the Two } \\
\text { Provinces and Cities in Building a Chengdu-City Urban Agglomeration" }\end{array}$ \\
\hline June 2016 & $\begin{array}{c}\text { Sichuan and Chongqing signed the "Key Work Program for Deepening the Pragmatic Cooperation in Sichuan and Chongqing } \\
\text { in } 2016 \text { " and } 10 \text { series of cooperation agreements. }\end{array}$ \\
\hline
\end{tabular}




\subsection{Establishment of Industry Guidance Fund}

The Chengdu-Chongqing Economic Zone is a place where China's "One Belt and One Road" economic belt merges with the Yangtze River Economic Belt. It is highly compatible with the national development strategy and local economic development needs. However, due to the administrative nature of financial resources, financial resources are difficult to achieve cross-regional cooperation. In recent years, the role of government in investing has been changing. Through the establishment of government-led funds, it has used market-based means to invest limited funds in promising industries, while attracting more private capital to participate in investment and boost local economic growth. Improve and adjust social capital allocation. Government-guided funds are viewed by the central and local governments as a favorable tool for advancing economic restructuring and industrial transformation and upgrading. In the context of supply-side structural reforms, the two cities in Sichuan and Chongqing can combine the guiding role of government funds and use market mechanisms to carry out government-to-government cooperation. Cooperation, through the capital market to promote cross-regional financial investment through government-guided funds for regional cooperation, in the Chengdu-Chongqing Economic Zone manufacturing has not yet been the first case. The government-guided funds have become a powerful tool to promote industrial transformation and upgrading and regional coordinated development and support regional economic development [5].

\subsection{The Existence of a Superior Industrial Base}

With the in-depth development of regional economic integration, the shift of eastern industries to the central and western regions has continued to increase, providing facilities for the development of the Chengdu-Chongqing Economic Zone. The Chengdu-Chongqing Economic Zone is an important industrial base in the country. The secondary industry occupies an important position in the gross domestic product, has a complete range of industries, a high degree of specialization, and a strong supporting capacity [6]. Electronic information, automobiles, medicine, food, petrochemical, etc. are the pillar industries in Sichuan, and Chongqing is also one of the eight old industrial bases in China. Automobiles and machinery occupy a pivotal position in the country. Among the 40 categories of industrial industries in the country, there are 39 in Chengdu-Chongqing Economic Zone, where industries such as electronic information, automobiles and motorcycles have considerable advantages, and provide favorable conditions for industrial cooperation in Chengdu-Chongqing Economic Zone.

\section{The Challenge of Government Cooperation in Sichuan-Chongqing Economic Zone}

\subsection{The Division of Government Functions is Not Clear}

The development of industrial cooperation between Chengdu-Chongqing Economic Zone lacks sufficient favorable countermeasures, competition is far greater than cooperation, the industrial division of labor is not clear, and the mechanism for coordinated development is not perfect. Judging from the auto industry of the two places, after the Chongqing became a municipality, the automobile industry in Sichuan almost disappeared. However, Sichuan did not focus on the development of automobile supporting industries. Instead, it introduced Toyota to try to revitalize the automobile industry, and the Chongqing Chang'an Group has nearly 300 car facilities. Among the enterprises, only a handful of companies are from Sichuan. Chongqing should give full play to the advantages of the automobile industry and spare parts supporting industries. It will establish auto parts factories in Sichuan, develop resources together, strengthen the convergence of industries in the two places, dislocate development support, and realize the sharing of benefits. The basis for regional cooperation is the division of labor. The governments of the two places should clarify the division of functions of the local market and expand the interest convergence points of the Chengdu-Chongqing Economic Zone so that the Chengdu-Chongqing Economic Zone can develop in a balanced manner [7].

\subsection{Severe Homogeneity of Industrial Structure}

In Sichuan and Chongqing, due to the serious industrial homogeneity, the functional division system in each region is not clear, and the same industry or several industries are often used as the key industries for development, resulting in investment based on their own development, which eventually leads to repeated investment. Great waste of resources [8]. Taking the electronic information industry as an example, both cities in Sichuan and Chongqing have listed the industry as 
an important growth point for future economic development. Such a game relationship is very easy to form a zero-sum game, in which one party's gains will lead to the loss of the other party and eventually affect the economy. Overall economic development in the area. Blindly pursuing its own economic development and grasping one-sidedly the economic situation in cooperation is the culprit behind the lagging economic development. Both governments can adopt a series of measures to enable Sichuan and Chongqing to promote the adjustment and upgrading of industrial structure in the industrial cooperation and strive for the final from the zero-sum game to a win-win situation, so as to jointly create an influential industrial cluster.

\section{Deepening the Strategy of Government Investment Cooperation in Chengdu-Chongqing Economic Zone}

\subsection{Promoting Regional Cooperation Mechanism Reform and Innovation}

The cooperation mechanism of innovative regions is conducive to the promotion of regional economic development and the elimination of market barriers and institutional obstacles. The Chengdu-Chongqing Economic Zone should focus on supply-side structural reforms to transform government functions, optimize industrial layout, give full play to the decisive role of regional markets in resource allocation, and actively handle the relationship between the government and the market. In the process of formulating decisions, the government should pay attention to the balanced development of all regions. The simple economic cooperation cannot provide assistance for the regional overall development. It is impossible to rely on local government's self-conscious behavior. It is also difficult to force the system to be pushed from top to bottom. Only through intergovernmental cooperation under the institutionalized cooperative development mechanism can regional coordinated development be achieved. At present, cooperation among various regional governments is still at a stage where there is no standardized system, such as the related consensus reached between the governments of Chengdu-Chongqing Economic Zone, the regular mutual visits system, the responsible person coordination conference system, etc. These preliminary cooperation development mechanisms have been reached. It is an assurance of cooperation between governments. Its goal is to achieve a regional economic transformation led by the government. However, because there is no standardized system, the efficiency of cooperation between governments is greatly reduced. Therefore, regional governments should actively promote regional cooperation. Mechanism reform and innovation.

\subsection{Increase the Construction of Innovative Industrial Clusters}

Under the background of economic integration, increasing investment in strategic emerging industries and developing industrial clusters will help promote industrial restructuring and balanced development of the regional economy. In 2012, the National Development and Reform Commission formally designated Guang'an as a model for the Chengdu-Chongqing Economic Zone and even the entire country. The establishment of a multi-level cooperation mechanism is conducive to the coordinated development of the Chengdu-Chongqing Economic Zone. Guang'an is committed to the outstanding industries in Chongqing, and actively strengthens the connection and support. The division of labor in the advantageous industries has greatly enhanced the degree of industrial fit. As a typical landlocked economy, Chengdu-Chongqing Economic Zone has a greater impact on industrial cluster construction than other three economic regions. In the process of concentrated industrial development in Chengdu-Chongqing Economic Zone, the government should accelerate the pace of industrial restructuring and transformation through innovation, promote the conversion of new and old kinetic energy in manufacturing industries, vigorously develop innovative industrial clusters, create new models, and deepen structural reforms on the supply side. In order to speed up the construction of a modern economic system, if only the role of investment promotion is played, regional clusters may only be concentrated in the geographic location of the enterprise. If there is a lack of correlation among the enterprises in the cluster, it will lead to excessive competition among similar enterprises. It will not be possible to increase regional competitiveness and cause a waste of investment and resources, leading to serious industrial homogenization. 


\subsection{Optimizing the Operation of Industrial Guidance Funds}

The emergence of government-guided funds as a new cooperation model helps the transformation and upgrading of industrial structures. In the past, fiscal funds rarely achieved cross-regional cooperation. However, the emergence of industry-led funds can pool resources across the country through capital markets. Utilize the resources of the fund industry chain to introduce advanced manufacturing industries in Sichuan and Chongqing to create industrial clusters, thereby contributing to the development of innovative industries and the transformation and upgrading of traditional industries. Chuanyu area fund managers can also negotiate and increase the operation of industrial guidance funds. Through the new model of industry-guided fund cooperation, industrial cooperation between Sichuan and Chongqing can be carried out to better play the role of the market. Good market mechanism, avoiding ineffective competition, cross-regional cooperation of funds through regional industrial integration, accelerating the development process of advantageous industries and innovative enterprises in Chengdu-Chongqing Economic Zone, and implementing national innovation-driven development strategic planning to increase growth. Oriented innovative enterprise investment fosters a group of innovative companies that are market-oriented and independent research and development as the driving force to achieve the optimal allocation of resources to bring vitality to the development of regional industries, promote the coordinated development of regional economies and realize the realization of real enterprises. Sustained development will help upgrade the industrial upgrading of the Chengdu-Chongqing Economic Zone and supply-side structural reforms.

\section{Summary}

Based on the analysis of the government investment cooperation between Sichuan and Chongqing under the motive of transformation and upgrading of manufacturing industry, this paper shows that regional coordinated development has become an important part of modern economic system construction. Chengdu-Chongqing Economic Zone is the core area for guiding the development of the western region and its economic development. It has a direct impact on the development of western China. The economic development of Chengdu-Chongqing Economic Zone requires the close and tacit cooperation between the two governments. Although government investment will have problems such as incentive deviation and inefficiency, the government still has significance in the transition process. Government investment has an important impact on the development of the industry. Therefore, it is still necessary to strengthen government investment, but it is not possible to rely on the government as it was before. Instead, it should use the institutional innovation to better play the role of the government in the context of transformation and upgrading and strengthen the role of the local government through government guidance funds. Mutual cooperation. The governments of Sichuan and Chongqing should strengthen cooperation on the basis of stronger economic and technological strengths and industries, choose a feasible development path under the strong driving force of radiation, and promote the stability of Chengdu-Chongqing Economic Zone through an efficient investment and cooperation model. Development, accelerate the transformation and upgrading of industrial structure, and effectively promote the integration of Chengdu-Chongqing Economic Zone, thus realizing the "simultaneous urbanization" of the two places.

\section{References}

[1]. Xu Shaoshi. Perfecting the New Type of Investment and Financing System and Mechanism to Meet the Requirements of Market Economy [J]. China's Economic and Trade, 2016(22):4-6.

[2]. Zhang Xiaowen, Yan Haixia. Promoting the Integration of Chengdu's Informatization and Industrialization [J]. Journal of Chengdu Administration Institute, 2013(6):78-82.

[3]. Liu Xiaoxia. Research on the selection of western strategic industrial chain: taking industry as an example [D]. Chongqing University, 2015. 
[4]. Wang $\mathrm{Yu}$. The formation of strategic decision-making in Chongqing under the Central Government [J]. Century Bridge, 2013(8):27-29.

[5]. Hao Qiujiang. A Study on the Cooperation Mechanism among Local Governments: A Case Study of Chengdu-Chongqing Region [J]. Northern Economic \& Trade, 2016(6):20-21.

[6]. You Peng. Research on the coordination mechanism of interest among local governments in the cooperative development of Chengdu-Chongqing Economic Zone [D]. Chongqing University, 2015.

[7]. Chen Zhangheng. Research on the Factors and Countermeasures of Restraining the Economic Integration of Chengdu-Chongqing Economic Zone under the Background of "One Belt and One Road" [D]. University of International Business and Economics, 2016.

[8]. He Xionglang, Yang Jirui. Thoughts on the Development of Chengdu-Chongqing Economic Zone [J]. Journal of Yibin University, 2010, 10(2):72-77. 